\title{
PRODUÇÃO E CONSUMO DE ALIMENTOS: NOVAS REDES E ATORES
}

Abel Cassol

Universidade Federal do Rio Grande do Sul (UFRGS), Porto Alegre, RS - Brasil. <abelcassol@hotmail.com>

Sergio Schneider Universidade Federal do Rio Grande do Sul (UFRGS), Porto Alegre, RS - Brasil.

<schneide@ufrgs.br >

http://dx.doi.org/10.1590/ 0102-6445143-177/95

Até meados do século XX, a sociologia manteve-se relativamente alheia aos estudos sobre alimentação e consumo de comida em face dos efeitos sociais decorrentes dos processos de mudança tecnológica, os quais atraíam mais a atenção dos analistas para o lado da produção e natureza dos processos produtivos e, posteriormente, das questões de distribuição (Ward, Coveney e Henderson, 2010). Durante boa parte da segunda metade do século XX, esse foi o foco central da sociologia rural e da sociologia da agricultura (Buttel, 2001). Nas últimas décadas, porém, os estudiosos passaram a problematizar e analisar sociologicamente o papel do consumo (Warde, 1997), as práticas alimentares (Mennell, Murcott e Otterloo, 1992) e as ações dos consumidores na conformação da identidade social ou de estilos de vida (Bourdieu, 2007), assim como novas formas de sociabilidade e identidade pelas formas de consumo de alimentos (Ritzer, 2007; Baumann, 2007).

Em larga medida, esse deslocamento da sociologia rural e da agricultura para a sociologia da alimentação e do consumo ocorreu de forma mais proeminente na Europa e 
na América do Norte. Entretanto, no Brasil e em outros países emergentes também já há estudos sobre esses temas. De modo geral, a sociologia da alimentação tem como objeto de estudo a interação entre os processos biológicos e sociais de produção, consumo e distribuição de alimentos, cujas relações envolvem conflitos e disputas, representações e identidades, além de estratégias econômicas e comerciais por comida e matérias-primas de origem primária.

Conforme destacaram Díaz Méndez e Gómez Benito (2004), os fundadores da sociologia haviam analisado a alimentação apenas como uma dimensão para compreender outras manifestações, como a religião, a desigualdade e o poder (Durkheim, 1996; Veblen, 1988; Weber, 1991). No decorrer do século XX, contudo, a sociologia passou a desenvolver estudos sobre o consumo, primeiramente preocupada em conhecer os comportamentos e valores sociais dos indivíduos afetados pelas novas formas de sociabilidade 144 capitalista emergentes (Simmel, 1986), e depois passou a se interessar pelas relações entre os meios de consumo e as posições sociais (status) ocupadas pelos atores (Baudrillard, 1995; Bourdieu, 2007).

Especificamente no âmbito dos estudos rurais, as discussões em torno da alimentação ganharam impulso a partir da consolidação do processo de globalização da produção e distribuição de alimentos, que passou a se concentrar cada vez mais nas mãos das grandes empresas transnacionais (Friedmann e McMichael, 1989; Friedmann, 1993). Mais recentemente, outros elementos também passaram a impulsionar a problemática sociológica dos alimentos, tais como (1) as questões de saúde pública (desnutrição e obesidade), (2) os problemas ambientais decorrentes da produção de alimentos (poluição e contaminação com agroquímicos) e (3) a opulência do consumo e o consequente desperdício de alimentos (Lang, Barling e Caraher, 2009; Morgan e Sonnino, 2010; Popkin, 2011). No Brasil, poder-se-ia acres- 
centar uma quarta dimensão à crescente problematização sociológica das questões alimentares, que se refere, de um lado, às ações de segurança alimentar e nutricional (SAN) e, de outro, às políticas e ações dirigidas para os agricultores familiares (Portilho, Castaneda e Castro, 2011; Guivant, Spaargaren e Rial, 2010).

De maneira geral, os resultados dos estudos mostram que a "questão alimentar" extrapola a dimensão da oferta de matérias-primas, fibras e alimentos, assim como os processos de organização produtiva (a agricultura em si) presentes no meio rural. O consumo de alimentos e o significado simbólico da comida e da alimentação obtiveram enorme reconhecimento. Desse modo, é possível dizer que houve um verdadeiro deslocamento analítico e questões e temas relacionados ao consumo e aos consumidores ganharam relevância (Goodman, 2002). Contudo, o atual debate acerca da alimentação e do consumo continua a se concentrar em autores europeus, que têm levantado a necessidade de uma "virada do consumo" nos processos e práticas relacionadas à produção, comercialização e consumo alimentares (D. Goodman, Dupuis e M. Goodman, 2012), destacando a importância do consumo para se compreender os modos de vida, as interações econômicas e as ações dos indivíduos.

Autores como Carolan (2012) afirmam que o estudo das relações do consumo e dos sistemas de produção agroalimentares é fundamental para a compreensão do comportamento e das ações dos indivíduos na sociedade moderna (Beck, Giddens e Lasch, 1995), assim como a conexão com a saúde coletiva (Díaz Méndez e Gómez Benito, 2008). O ato de comer passa a ser bem mais do que uma ação hedonista, torna-se uma ação social com sentido capaz de gerar novos valores e modos de vida sustentáveis (Barbosa e Campbell, 2006; Barbosa, 2009). O consumo e os consumidores, por sua vez, passam a ser vistos como atores reflexivos e agentes políticos, conscientes de que o ato de consumir tem relação 
com a preservação do meio ambiente, a qualidade dos alimentos, a forma como estes são produzidos e os impactos sociais que podem estar gerando (Seyfang, 2009).

É nesse contexto que inúmeros estudos sobre novas formas de produção e consumo alimentares vêm sendo produzidos, notadamente a partir da análise de diferentes mercados (ou redes) locais em que suas relações se manifestam (Brunori, 2007; Fonte, 2010). De acordo com D. Goodman, Dupuis e M. Goodman (2012), essas novas formas (alternativas) de provisão alimentar são capazes de construir práticas materiais e imaginárias assentadas em valores e racionalidades transformadoras da lógica instrumental capitalista. Nesse sentido, o desenvolvimento das redes alimentares (tais como os movimentos de fair trade, as cadeias curtas etc.) poderiam gerar práticas econômicas alternativas, que diferem das formas capitalistas de produção, distribuição e consumo de alimentos. Segundo os autores, isso ocorreria pelo fato de que as redes 146 alternativas de abastecimento agroalimentar estariam assentadas em valores territoriais, assim como imersas em construções e convenções sociais que atribuem aos alimentos outros juízos de julgamento e valoração ligados aos valores sociais e culturais das regiões nas quais são produzidos e consumidos.

De fato, uma parte significativa dos estudos indica que os processos de constituição de novas formas e relações entre a produção e o consumo de alimentos são permeadas por formas de sociabilidade assentadas no interconhecimento e em redes sociais (Marsden, Banks e Bristow, 2000; Marsden, Banks e Renting, 2003; Brunori, 2007). O aspecto em comum destacado nessas análises é o reconhecimento de que a sociabilidade se traduz em vínculos que são capazes de criar valores sociais e culturais que estão enraizados na história, na cultura e nos territórios locais, fazendo com que a produção, o consumo e a circulação dos alimentos seja a base sob a qual novas relações sociais são estabelecidas (Goodman, 2002). 
Em síntese, esta literatura sugere que a interação entre as formas de produzir e comercializar e os modos de consumir e alimentar são cruciais para desenvolver práticas sustentáveis tanto de produção quanto de consumo. E estas análises acabam informando o campo de ação das políticas públicas, o papel dos atores e mediadores sociais e suas formas de organização, que passam a ser vistos como os atores que poderiam estimular a emergência de formas alternativas de produção, comercialização e consumo de alimentos (Marsden, Banks e Renting, 2003).

No caso brasileiro, pouca atenção tem sido despendida à questão da alimentação e, menos ainda, do consumo de alimentos em uma perspectiva sociológica. O debate sobre a alimentação e suas distintas formas de organização tem se restringido ao papel desempenhado pelo assim chamado agronegócio e um pouco pela análise de (novas) experiências que aproximam produtores e consumidores. Este é o caso, por exemplo, das tradicionais feiras livres da região Nordeste, anteriormente estudadas por Garcia (1992, 2008), assim como das recentes políticas públicas que vêm sendo implantadas no país (Programa de Aquisição de Alimentos PAA e Programa Nacional de Alimentação Escolar - PNAE), as quais são exemplos de formas diversificadas de mercados e organização alimentar, em que produtores e consumidores interagem. Vale registrar que a antropologia da alimentação tem feito esforços interessantes para estudar as práticas alimentares como dimensões da identidade e/ou da cultura.

Tomando esse debate como referência, este artigo pretende contribuir com as discussões sociológicas contemporâneas acerca das (novas) relações de produção e consumo no setor agroalimentar. O objetivo central deste artigo consiste em analisar as formas alternativas de abastecimento e produção alimentar através do entendimento do papel desempenhado pelos consumidores nesse processo. O campo de observação para realização do estudo 
foram dois grupos coletivos de aquisição de alimentos e as feiras de venda direta.

$\mathrm{O}$ artigo se estrutura em três seções principais. Na primeira delas, se discute a abordagem das novas formas de produção e consumo que vêm sendo analisadas nos estudos rurais, as chamadas redes agroalimentares alternativas (alternative food networks). Aqui o objetivo é discutir as principais características desse processo e suas implicações para pensar questões como construção social de mercados alternativos, qualidade e produção local de alimentos vinculada aos valores sociais e culturais dos territórios onde emergem.

A segunda seção é reservada à descrição e apresentação de casos empíricos dessas redes (e mercados) que vêm sendo construídas e consolidadas em diferentes partes do mundo. Em especial, discutiremos as principais questões em torno da rede de consumidores do GAS (Grupo de Aquisição Solidária), na região de Pisa na Itália, analisando como a criação e 148 operação dessa rede partiu da iniciativa dos próprios consumidores da região, assim como analisaremos o caso da Feira do Pequeno Produtor de Passo Fundo, no Estado do Rio Grande do Sul, cujo mercado foi construído e é gerido por um grupo de agricultores familiares do município.

A terceira seção volta-se à questão do consumo no interior dessas redes agroalimentares, em que buscamos demonstrar como os consumidores podem ser vistos como agentes importantes na mudança rumo a práticas de consumo mais sustentáveis. O objetivo aqui foi o de problematizar quem são esses consumidores "alternativos" e quais valores estão orientando suas práticas cotidianas de consumo. Para encerrar, nas conclusões apresentamos algumas considerações e apontamentos que visam propor uma nova agenda de pesquisas para a sociologia rural, que incorpore a dimensão do consumo enquanto uma variável chave para a compreensão da alimentação contemporânea, destacando o papel desempenhado pelos mercados alimentares locais nesse processo. 


\section{Redes agroalimentares alternativas: construção social de mercados, embeddedness e território}

Já faz algum tempo que os estudos rurais vêm chamando a atenção para a necessidade de mudança do modelo agroalimentar e agrícola convencional em direção a formas mais sustentáveis de coprodução entre sociedade e natureza. Alguns autores chegaram a postular a necessidade de superação do modelo produtivista de agricultura e sugerem uma transição para um modelo de desenvolvimento rural (Van der Ploeg et al., 2000). Essa "virada analítica" é caracterizada pela emergência de estudos que enfatizam formas alternativas de produção e consumo, os quais estão preocupados em analisar a criação, operação e consolidação dessas novas relações e padrões no interior do sistema agroalimentar.

Tais análises refletem o surgimento de novas formas de produção e consumo, que emergem como resposta e alternativa aos diversos questionamentos sobre os limites e incongruências da agricultura moderna (problemas ambientais, insegurança alimentar, alimentos processados industrialmente e sem valor nutritivo), que ganham força e destaque a partir da década de 1990 (Goodman, 2002). Nesse sentido, a literatura em torno das redes agroalimentares alternativas se fundamenta na crítica ao sistema político e econômico ligado às grandes empresas e corporações que dominam a produção e distribuição dos alimentos, reivindicando questões de justiça social, produção sustentável, cadeias curtas de produção, valorização de mercados de produtos locais e singulares (Thomé da Cruz, 2012).

Esse processo acaba por reconhecer a reflexividade dos consumidores e que os agricultores são cada vez mais instados a desenvolver novas formas de produção e comercialização que contribuam para a relocalização e o quality turn do sistema agroalimentar (Goodman, 2002; Harvey, McMeekin e Warde, 2004). Assim, produção e consumo se assentam em um tripé baseado em dimensões relativas ao 
produto (que está ligado à origem/procedência deste), ao lugar (ligado ao território e à identidade) e ao processo (expresso pelo saber-fazer específico e da cultura de cada região/agricultor) em que os alimentos são produzidos, transformados, distribuídos e consumidos (Ilbery e Bowler, 1998). Esse processo de relocalização tem sido analisado a partir de diversos enfoques, seja através de dimensões/processos políticos (slow food; boicote a produtos não sustentáveis etc.), pelo viés das políticas públicas e/ou das novas formas de produção e relação entre produtores e consumidores.

Em quaisquer desses enfoques, os consumidores emergem como o novo ator-chave para as interpretações acerca da "questão alimentar" contemporânea (Goodman, 2002; Portilho, Castaneda e Castro, 2011). São eles que passam a desempenhar um papel inovador nas formas de organização dos processos de produção (demand driven), resultan150 do na criação daquilo que Marsden e colaboradores (2000; 2003) denominaram de cadeias curtas de abastecimento, que consiste em uma iniciativa de aproximar os agricultores que produzem e os consumidores que consomem. Segundo esses autores, tal processo está na origem do desenvolvimento das redes agroalimentares alternativas, que se contrapõem às redes longas formadas pelas grandes cadeias do agronegócio globalizado.

A característica central das cadeias curtas de produção e comercialização está relacionada à distância física de extensão e percurso entre os produtores primários e os destinatários finais dos alimentos, em contraposição aos circuitos longos formados por cadeias industriais de abastecimento que distanciam e separam cada vez mais esses atores entre si. Na prática, as cadeias curtas acabam formando redes alimentares alternativas ao modo convencional, pois são formadas por produtores, consumidores e outros atores que buscam "alternativas" ao modo industrial de abasteci- 
mento alimentar. Essas redes referem-se a agentes que estão diretamente envolvidos na produção, processamento, distribuição e consumo dos produtos alimentares. Como principais características, esses tipos de cadeias agroalimentares engendram diferentes relações com consumidores e podem envolver diversas convenções e construções de qualidade, embasadas no enraizamento social (embeddedness), hábitos e cultura alimentar locais e regionais em que tais relações estão imersas e através das quais esses novos mercados são socialmente construídos.

No Brasil, esse debate ainda é incipiente, ainda que alguns autores venham desenvolvendo trabalhos com essa perspectiva. Radomsky (2010), por exemplo, analisou como a construção da rede ECOVIDA está assentada na manutenção de um estilo de vida ecológico - tanto dos produtores quanto dos consumidores -, permitindo a construção e atribuição de significados aos alimentos comercializados por ela. Ferrari (2011) analisou o processo de construção social dessas formas de produção e comercialização no Estado de Santa Catarina. Ao analisar três casos empíricos, o autor demonstra como os agricultores daquela região vêm construindo alternativas ao modelo convencional de produção ao utilizar estratégias de agregação de valor e inserção dos seus produtos em mercados específicos, aproximando produtores e consumidores e desenvolvendo relações de confiança entre ambos.

Também em Santa Catarina, Scarbelot (2012) estudou como fatores históricos e conjunturais - associados à etnia italiana - contribuíram para o desenvolvimento e consolidação de formas alternativas de produção, processamento e distribuição alimentar por parte dos agricultores e consumidores no Município de Nova Veneza, região sul daquele estado.

Em todos esses casos, portanto, reconheceu-se a capacidade que os próprios atores sociais têm de criar e construir formas alternativas de produção e comercialização 
alimentares, ou seja, de desenvolver novas formas de mercado (Long e Van der Ploeg, 2011). Além disso, esses exemplos demonstram como os mercados alimentares têm emergido enquanto formas de inclusão social para um contingente considerável de pequenos agricultores em distintas regiões.

Nesse sentido, essas redes alternativas engendram uma miríade de relações sociais e culturais que estão no interior dos territórios nos quais emergem, fazendo com que as transações econômicas aí realizadas estejam imersas nesses valores e sejam influenciadas por eles.

Como veremos adiante, experiências empíricas desse tipo de rede agroalimentar permitem que significados e valores sociais sejam atribuídos aos alimentos. Por sua vez, esses significados e valores variam de acordo com a realidade social e as características de cada região.

\section{Alternatividade das redes agroalimentares "alternativas"}

Diversos são os estudos que reivindicam a necessidade de problematização do processo de quality turn evidenciado nas teorias acerca do sistema de abastecimento agroalimentar atual (Goodman, 2002). Esses estudos têm como principal objetivo discutir a ideia antípoda entre produção de alimentos locais imersos versus produção de alimentos globais "desimersos", adotada por diferentes autores ${ }^{1}$.

O desenvolvimento de novas formas de produção e consumo alimentar está vinculado ao processo mais geral denominado de "virada da qualidade" (quality turn), em que a questão agroalimentar passa por um movimento em direção à qualidade alicerçada na confiança, na tradição local e em novas formas de organização econômica. Segundo

\footnotetext{
1 Alguns autores chamaram a atenção para o cuidado em tomar o local (place) como algo puro, onde não há relações de poder e dominação. Especificamente, eles defendem a produção local como uma estratégia e não como solução ao sistema agroalimentar dominante. Ver, por exemplo, Born e Purcell (2006).
} 
Goodman (2002), a revalorização que as redes alimentares alternativas permitem vinculam as práticas alimentares aos territórios rurais (locais), tornando-os capazes de desenvolver "novos espaços econômicos", ou espaços "alternativos" ao convencional.

Para Sonnino e Marsden (2006), esse processo de quality turn - e a consolidação das redes alimentares alternativas assume características distintas de acordo com o contexto político, os atores sociais e a história de cada território ao qual estão vinculadas. Portanto, definir o que é qualidade e o quão "alternativo" essas redes são depende das características dos contextos sociais em que se encontram².

Em virtude de surgirem como respostas às crises econômicas, sociais e de saúde pública geradas pelo modelo agroalimentar convencional, essas redes alternativas sugerem, intrinsecamente, que há uma oposição entre modelos de produção e consumo de alimentos. Todavia, ao se analisar processos empíricos, verifica-se que as fronteiras entre ambos os modelos não são tão rigorosas e claramente delimitadas, conforme a seguir se analisa.

De acordo com Fonte (2010), embora os modelos convencional e alternativo sejam quase sempre considerados antagônicos, eles operam em um mesmo espaço econômico, interseccionando e sobrepondo-se um ao outro. $\mathrm{Ou}$ seja, não podemos falar de um modelo alternativo e outro convencional de forma ideal, uma vez que, na realidade, ambos formam redes que se relacionam, se comunicam e até mesmo se justapõem (Thomé da Cruz, 2012).

D. Goodman, Dupuis e M. Goodman (2012) argumentam na mesma direção da coexistência desses modelos, sendo as formas "alternativas" geralmente apropriadas pelo modelo "convencional", com o intuito de responder

\footnotetext{
2 Para maiores detalhes das diferenças de surgimento e funcionamento dessas redes em distintas regiões e contextos, ver Goodman (2002) e Fonte (2008).
} 
a demandas de consumidores por produtos sustentáveis e mais justos.

Segundo esses autores, o desenvolvimento dessas redes assumem características diferenciadas, dentre as quais podemos distinguir cadeias agroalimentares locais (local food) e cadeias agroalimentares localizadas (locality food). Ao enfatizarem a necessidade de aprofundar as análises sobre as relações sociais existentes nesses espaços - que eles consideram muito pouco estudadas se comparadas com as questões ecológicas e os resultados materiais que elas proporcionam -, os autores discutem a questão da alteridade que essas redes detêm em relação ao sistema convencional e as reflexividades que ali se confrontam quando analisamos o papel dos consumidores.

Para Goodman, Dupuis e Goodman (2012), os alimentos localizados (locality food) são aqueles nos quais selos de origem e procedência são imputados para o reconheci154 mento da qualidade atribuída aos produtos. Nesses casos, o objetivo buscado, geralmente, é um aumento de escala, fazendo com que esses produtos passem a ser consumidos não mais em nível local, mas em nível regional e internacional. Assim, a alteridade dessas redes se dá a partir dessa mudança de escala, implicando em adoção de novos padrões e convenções de mercado e de governança que são diferentes das relações locais face a face e das convenções domésticas de qualidade anteriormente adotadas. Nesse sentido, asseveram os estudiosos, essas redes encontram-se mais fortemente vinculadas aos mercados alimentares convencionais, como tem ocorrido, recentemente, com muitos grupos varejistas incorporando tais produtos às suas lojas (caso do Carrefour, Tesco e Wal-Mart).

Por outro lado, os alimentos locais (local food) são caracterizados por redes de produtores e consumidores locais, que podem ou não possuir selos de origem ou procedência, mas que permitem que outras formas de interação, para 
além da mercantil, possam existir. Nessas redes, a alteridade é atribuída às relações interpessoais, aos processos de trocas localizadas e personalizadas, permitindo um engajamento ético e político e o estabelecimento de relações igualitárias entre produtores e consumidores.

Nesse sentido, o importante a reter é que não se deve tomar a produção local de alimentos enquanto espaço puro, em que não há relações de poder e competição entre os diferentes atores. Segundo Born e Purcell (2006), é preciso ter cuidado para não confundir as relações espaciais que essas redes possibilitam (produção em âmbito local), com as relações sociais a elas subjacentes (poder, confiança, interação pessoal, embeddedness), que necessitam ser mais bem analisadas (D. Goodman, Dupuis e M. Goodman, 2012, p. 71).

$\mathrm{Na}$ verdade, as redes alimentares locais parecem ser mercados híbridos em que podem ser encontradas tanto relações convencionais de produção e consumo, como relações alternativas (Sonnino e Marsden, 2006). Essas redes não devem ser vistas enquanto formas de oposição (no sentido de confrontação) aos mercados agroalimentares convencionais, mas como formas diferenciadas de produzir e consumir no interior do sistema capitalista. No entanto, não há porque imaginar que essas redes não possam estabelecer relações mercantis e de trocas diferenciadas, contribuindo com a construção de regimes sustentáveis e mais justos entre os atores participantes. Dessa forma, esses espaços são construídos e mantidos por uma diversidade de atores e instituições, os quais adotam lógicas e processos distintos, que podem ser contestados e/ou legitimados em nível local.

Antes de analisar especificamente a questão do consumo, apresentamos duas experiências empíricas com o intuito de descrever as principais características, diferenças e semelhanças que possam ajudar a compreender as questões até aqui expostas. 


\section{Estratégias alimentares e de abastecimento locais: o caso do Grupo de Aquisição Solidária (GAS) italiano e a Feira do Pequeno Produtor de Passo Fundo (RS)}

A escolha por analisar comparativamente esses dois casos justifica-se pelo interesse em verificar de que modo as teorias e conceitos utilizados na Europa se ajustam à realidade brasileira, ainda carente em estudos que tratam das relações entre produção e consumo alimentar. A opção adotada também se justifica pelo fato de um dos objetivos do artigo buscar demonstrar como mercados alimentares localizados possuem características de funcionamento, gestão e valorização distintas, de acordo com os contextos sociais e culturais (históricos) nos quais emergem. Nesse sentido, a comparação entre duas regiões bastante diferenciadas em termos históricos e sociais permite que esses elementos sejam evidenciados. Outro fator que justifica essa escolha se deve à possibilidade de demonstrar como ambos os mer156 cados constituem-se em formas consolidadas de inclusão social dos agricultores familiares em cada uma das regiões selecionadas.

A metodologia utilizada foi a do estudo de caso da Feira do Pequeno Produtor de Passo Fundo (RS), em que a coleta de dados ocorreu por meio de entrevistas e da aplicação de questionários semiestruturados ${ }^{3}$. Os dados sobre a Feira fazem parte de um estudo mais amplo, no qual as questões da emergência desse mercado alimentar, suas formas de funcionamento e os valores sociais e culturais que orientam

\footnotetext{
3 No total, foram aplicados 45 questionários semiestruturados aos consumidores da Feira e 25 aos feirantes. A escolha desses indivíduos obedeceu a um critério de amostra intencional, ou seja, não foi calculado um número prévio de questionários a serem aplicados, ao passo que as respostas foram sendo repetidas, cessaram-se as aplicações. Além dos questionários, foram realizadas 25 entrevistas em profundidade (com roteiro de perguntas), sendo 12 com feirantes, 7 com consumidores e 3 com representantes de instituições de mediação (Emater, Secrint e STR). O período de coleta de dados deu-se entre os meses de abril a novembro de 2012 (Cassol, 2013).
} 
as práticas econômicas foram analisados de forma mais profunda (Cassol, 2013).

Em relação ao GAS da Itália, a metodologia utilizada baseou-se em revisão da literatura sobre os casos estudados por Brunori e colaboradores (2007, 2010a, 2010b). A escolha desse caso, conforme referido, justifica-se em face de sua especificidade em relação a outras formas de organização dos mercados alimentares locais. Além disso, o caso italiano reporta-se a uma região historicamente vinculada à produção de alimentos tradicionais.

Dessa forma, num primeiro momento, discutimos a experiência do GAS na Itália, o qual se constitui como uma rede de consumidores que compram seus produtos de pequenos agricultores pela internet, podendo escolher os produtos que desejam antecipadamente; e também em feiras livres organizadas semanalmente em diferentes regiões (Brunori et al., 2010a, 2010b). Na sequência, apresentamos o caso do mercado alimentar da Feira do Pequeno Produtor de Passo Fundo, região norte do Estado do Rio Grande do Sul, com o objetivo de analisar como as interações entre agricultores e consumidores vêm influenciando e transformando as práticas de produção e consumo naquele município.

Secundariamente, também analisamos as principais semelhanças e diferenças entre esses dois mercados em relação às formas de interação entre os atores (e os valores que são capazes de gerar e sobre os quais se apoiam), os ativos (recursos) e formas de governança associados ao contexto social em que estão situados.

\section{O Grupo de Aquisição Solidária (GAS) na Itália:}

\section{uma rede local a partir dos consumidores}

De acordo com Brunori et al. (2010a; 2010b), o GAS é um grupo de compras organizado por consumidores italianos que construíram diversas redes de relações ao redor 
do consumo de alimentos frescos e saudáveis na região de Pisa, na Toscana ${ }^{4}$. Boa parte desses consumidores pertence a outras associações e grupos ligados a iniciativas alimentares (movimentos de fair trade, associações ambientais etc.), permitindo ligações estáveis com outras redes que também buscam construir alternativas.

Esses consumidores, por sua vez, estão ligados a uma rede de pequenos agricultores que são responsáveis pelo abastecimento e atendimento das demandas alimentares da rede. De forma geral, esses produtores trabalham com pequenas escalas de produção e com produtos orgânicos, baseados na diversificação das atividades e na conexão entre conhecimentos tradicionais (saber-fazer cultural da região) e inovação (ligação direta com os consumidores participantes da rede) (Brunori et al., 2010b, p. 11).

A Figura 1 esquematiza as redes de relações do GAS, ilustrando a interação relacional estabelecida entre pro158 dutores e consumidores que dela fazem parte. Np1 são os "novos camponeses" (neo-peasant), os quais possuem diversos contatos com os consumidores $(\mathrm{c} 1, \ldots, \mathrm{cn})$, porém estão relativamente desconectados dos produtores locais no território. Dessa forma, esses agricultores desenvolvem ligações com outros locais, criando "comunidades virtuais", as quais são geridas e apoiadas sobre listas de e-mails, blogs e sites na internet. Por sua vez, os agricultores locais (Lf1, ..., Lfn) constroem redes localmente mais densas, todavia possuem menos contato direto com os consumidores e maior interação com intermediários (int) ${ }^{5}$. Desvincular esses produtores

\footnotetext{
4 Apesar de ter surgido na Toscana, cabe destacar que a rede que forma o GAS estende-se a diversas regiões italianas e compreende uma grande variedade de grupos de consumidores e produtores de norte a sul do país (Brunori et al., 2010a).

5 As diferenças entre os "novos camponeses" e os agricultores locais é que os primeiros são pessoas que se estabeleceram na região da Toscana a partir dos anos 1970, desenvolvendo agricultura orgânica e multifuncional; já os segundos são pessoas com experiência familiar na agricultura, que são nativos da região e possuem fortes laços com a comunidade local (Brunori et al., 2010b).
} 
Figura 1

Redes de relações constituídas entre produtores e consumidores do GAS

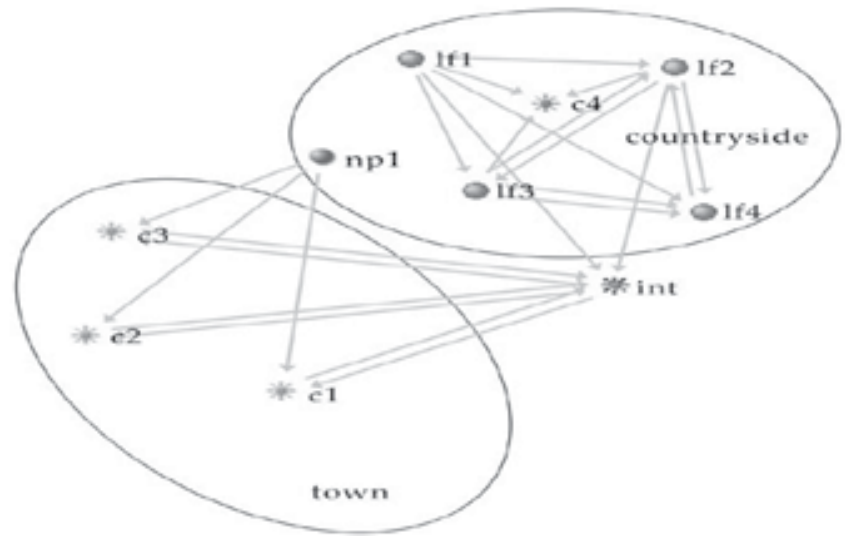

Fonte: Brunori et al. (2010b, p. 34).

locais dos intermediários e integrá-los ao GAS implica a possibilidade de reconectar toda uma rede social presente no território (Brunori et al., 2010b, p. 34).

Nesse sentido, a rede do GAS proporciona uma troca intensa de informações, a identificação de problemas e iniciativas comuns entre as diversas redes e sub-redes que são capazes de manter ${ }^{6}$. Claramente há um compartilhamento de conhecimentos e informações entre os integrantes e instituições participantes da rede, o que contribui para consolidá-la diante de outras formas de comércio e produção alimentar.

Essas trocas estão presentes quando da seleção dos agricultores por parte do grupo de consumidores, os quais levam em conta a aderência destes a princípios de sustenta-

${ }^{6}$ Por exemplo, diversos produtores da rede do GAS estão conectados a outros produtores de produtos tradicionais, tais como o queijo Parmigiano Reggiano, produtores de maçãs e laranjas orgânicas que não fazem parte da "rede principal", mas que mantêm relações estáveis com esta. 
bilidade produtiva e de consumo. Ainda, os produtores são escolhidos pelo tipo de produto que produzem e a distribuição é organizada de acordo com isso: caixas com vegetais, frutas e pães, queijos, massas e cereais etc. (Brunori et al., 2010b, p. 33).

Portanto, o contexto relacional é criado pela comunicação estabelecida entre os atores, assegurada pela troca de e-mails, pela interação direta (face a face), encontros organizacionais e visitas às propriedades. Esse processo facilita a troca de informações, define regras e constrói estratégias de atuação comuns entre produtores e consumidores.

Em relação às características principais de funcionamento e legitimação desse mercado, Brunori et al. (2010b) mencionam a questão da reputação e da confiança como valores essenciais na visão ética atribuída aos produtores pelos consumidores. Segundo os autores, esses valores dão aos produtores melhores posições no mercado: nos 160 melhores casos, a confiança substitui a barganha, tornando desnecessária a certificação dos produtos e reduzindo os custos de transação. A estratégia de sobrevivência dos produtores do GAS é centrada na qualidade, e a negociação e a construção desse atributo no interior da rede estão vinculadas à sazonalidade e à provisão/produção local dos alimentos consumidos, através dos quais características como "frescor", variedade, sabor e valor nutricional tornam-se essenciais. Atributos de qualidade como tamanho e formato, cor, integridade - característicos do modelo agroalimentar convencional - não são considerados relevantes enquanto estratégia de sobrevivência e atribuição de qualidade aos produtos.

Nesse sentido, o funcionamento desse mercado depende muito mais de "ativos imateriais" - como a confiança e a reputação - do que de "ativos materiais" - tecnologia, maquinário, embalagens. Ou seja, a manutenção dessa rede - e dos agricultores que dela fazem parte - está ligada a 
uma base de recursos endógenos, conhecimentos e habilidades, que são produzidos e reproduzidos pela interação no interior da rede. E são justamente os produtos fabricados a partir desses conhecimentos e habilidades que são buscados pelos consumidores.

Finalmente, esse tipo de mercado permite a consolidação de formas relacionais de interação entre produtores e consumidores. Na verdade, todo o sistema está baseado nas relações que podem ser estabelecidas entre esses dois lados, por meio das quais uma base de valores e princípios comuns é construída e compartilhada, promovendo formas sustentáveis de produção e consumo.

Dentre essas formas de interação, podemos destacar a possibilidade de os consumidores aprenderem e terem acesso a informações práticas de produção, técnicas e formas de fazer, além dos problemas e dificuldades por vezes ocorridos (p. ex., danos por mau tempo, doenças e pragas na plantação etc.) na produção dos alimentos. Conforme os autores, há um reconhecimento dos produtores na necessidade de compartilhar esse conhecimento com os consumidores, e estes estão interessados em saber mais sobre isso (Brunori et al., 2010b, p. 39). E também o ato de consumir dessa forma ajuda os consumidores a melhor se informar sobre a natureza da agricultura em si - suas rotinas, dificuldades e satisfações -, possibilitando a superação da visão romântica por vezes associada ao rural e à agricultura.

Ao analisar o caso do GAS, percebemos como as relações pessoais e o compartilhamento de valores - concretizados na comunicação entre as partes - possibilitam que formas (alternativas) de produção e consumo se estabeleçam e perdurem. Todavia, essas características (alternativas) variam de acordo com os contextos sociais aos quais estão vinculadas e, por isso, diferem entre si, como veremos ao analisar o caso da Feira do Pequeno Produtor de Passo Fundo. 


\section{A Feira do Pequeno Produtor de Passo Fundo (RS): uma rede local a partir dos produtores}

Diferentemente do caso italiano, a Feira do Pequeno Produtor de Passo Fundo foi fundada em 1975 pela iniciativa de doze pequenos produtores rurais do município que viram, nesse tipo de comércio, uma possibilidade para vender seus produtos diariamente aos consumidores e agregar maior valor aos mesmos. A ideia era trazer os produtos para o centro da cidade e vendê-los diretamente aos consumidores.

Hoje, passados quarenta anos de sua fundação, essa Feira se encontra consolidada no município e possui 66 feirantes atuantes, que trazem seus produtos para serem vendidos todas as segundas, quartas e sábados da semana, atraindo um número considerável de consumidores que vem até esse espaço em busca de alimentos de qualidade ${ }^{7}$.

Essa rede alimentar que é a Feira inclui, para além da Associação dos Feirantes - órgão responsável pela gestão 162 e organização da Feira -, o Sindicato dos Trabalhadores Rurais (STR), que atua desde o início da Feira e é responsável pela prestação de serviços e orientações aos agricultores (crédito, financiamentos, inserção em programas estatais), a Emater (Empresa de Assistência Técnica e Extensão Rural) do município - para a qual são atribuídas questões técnicas de produção e orientações de comercialização, e a Prefeitura Municipal, através da Secretaria do Interior (Secrint), que era a responsável pela gestão da Feira até 1996, e que, após a criação da Associação dos Feirantes, tem como principal atribuição fiscalizar os preços e a qualidade dos produtos vendidos.

Essa fiscalização é feita por um fiscal (da Secrint) que, ao início de cada mês, realiza uma pesquisa de preços dos

\footnotetext{
7 Vale lembrar que nem todos os feirantes são agricultores. Quatorze deles, uma minoria, não produzem os alimentos que vendem, mas compram seus produtos em outros locais e os negociam na Feira, atuando como comerciantes (Cassol, 2013).
} 
principais produtos vendidos na Feira em, pelo menos, dez supermercados e/ou fruteiras do município. Após esse levantamento, é calculada a média de preços para cada produto e os feirantes são orientados a comercializar seus alimentos a um preço $20 \%$ mais barato que essa média. Em relação à qualidade, o fiscal, nos dias de Feira, faz-se presente e dialoga com os feirantes principalmente em relação ao cumprimento de boas práticas de produção e conservação de seus produtos, ainda que esse processo não seja explícito aos consumidores (Cassol, 2013, p. 141).

De forma geral, os feirantes que dela participam são agricultores familiares do entorno do município, que vendem produtos tradicionalmente produzidos naquele território, respeitando a sazonalidade da produção. Há, entre estes, produtores de hortaliças, verduras e frutas, assim como um bom número de agricultores que transformam seus produtos através da agroindústria e vendem queijos, pães, cucas e salames, de modo que os consumidores que buscam esse espaço podem encontrar produtos frescos, de época, e que se diferenciam pela qualidade.

De forma esquemática, podemos demonstrar o funcionamento da rede da Feira do Pequeno Produtor na Figura 2. Como vemos, há duas dimensões interligadas que estão em constante troca, exemplificadas pelos agricultores familiares e os consumidores. Por sua vez, além da interação direta possibilitada entre ambos no espaço social e econômico da Feira, há também uma troca implícita de significados e uma (re)aproximação entre o meio rural e o meio urbano. Quer dizer, além de permitir a aproximação (física) de produtores e consumidores, o mercado da Feira também possibilita uma (re)aproximação simbólica entre a zona rural e a zona urbana, estreitando laços e definindo posições sociais de seus atores. Finalmente, todo esse processo de troca e interação é legitimado, fiscalizado e respaldado pelas instituições de mediação que também fazem 
parte e compõem o mercado da Feira, agindo como um elo que liga produtores ao Estado e garantindo aos consumidores a legalidade dos processos de produção dos alimentos.

Assim como no caso do GAS, a valorização dos produtos da Feira, tanto por parte dos produtores como por parte dos consumidores, se dá sobre aspectos imateriais relacionados à possibilidade de comprar alimentos "frescos", "da própria terra", produzidos ali mesmo no entorno do município e que se diferenciam pelo sabor e pela forma como foram feitos.

\section{Figura 2}

Esquema de funcionamento da rede da Feira do Pequeno

Produtor de Passo Fundo (RS)

Instituições mediadoras

(Emater, STR, Secrint)

Agricultores familiares

(Zona Rural)
Consumidores

(Zona Urbana)

Feira do Pequeno

Produtor

Fonte: Cassol (2013, p. 120).

Do lado dos consumidores, se distinguem nitidamente pelo menos dois grandes grupos: aqueles consumidores que apenas "vêm comprar" os alimentos e não interagem de forma significativa com os feirantes, não costumam pechinchar e, geralmente, não têm preferência declarada por produto ou produtor; o outro grupo são os consumidores "fiéis", os quais tratam os feirantes pelo nome, já vêm à Feira em busca de um produto específico que sabem onde encontrar, trocam informações as mais variadas com os fei- 
rantes e são os que demonstram mais apelo às questões da origem dos produtos, seu modo de produção (orgânicos ou não) e dos valores sociais e culturais empregados na produção (Cassol, 2013).

Todavia, apesar dessas diferenças marcantes, há em comum em ambos os grupos a atribuição da confiança (ou a valoração) da Feira na qualidade maior dos produtos em relação a outros tipos de comércio alimentar. Essa qualidade, por sua vez, parece estar ligada a uma espécie de representação social coletiva de que os produtos vendidos na Feira, além de serem mais "frescos", são também os que melhor remetem às formas de produção e preparo (transformação) ligadas aos valores culturais da região.

Diferentemente do caso do GAS, onde a própria extensão dos laços da rede contribui para a dissolução de uma visão romântica, idealizada do rural, no caso da Feira do Pequeno Produtor é justamente a referência positiva a formas idealizadas de relações com os alimentos (e às relações sociais) que está por trás da valorização e da busca dos produtos por parte dos consumidores. Ao contrário da Itália, a urbanização no Brasil é relativamente recente e, por isso, muitos consumidores, ao afirmarem por que compram na Feira, fazem referência a um passado rural idílico, "puro", e isso é transferido aos alimentos que são produzidos daquela forma (antepassada, tradicional) pelos produtores.

Durante a realização do trabalho de campo foi possível observar respostas do tipo "venho comprar nesta banca porque o pão dele é feito igual como minha mãe fazia"; "não sei se estou pagando um preço maior ou menor pelos produtos, mas compro deles porque meus pais eram agricultores" (Cassol, 2013, p. 138).

Assim, a qualidade atribuída aos produtos está relacionada a uma representação social compartilhada de que os alimentos da Feira - em comparação com outros mercados alimentares da região - são aqueles que melhor remetem às 
formas de produção e preparo ligadas aos valores culturais da região. Conforme dois consumidores entrevistados:

É por isso que eu compro [...] pela qualidade dos produtos... porque tem mercados... aqui em Passo Fundo tem mercados que tu encontra o que você quer, mas a questão de qualidade, tudo fresquinho... eles colhem de tarde e na outra manhã já estão ali, tudo muito bom [...] a questão não é por preço, porque aqui em Passo Fundo tem mercados que tu encontra preços mais baratos que a Feira [...]. (Entrevista 17. Consumidora, 39 anos, dona de restaurante) (Cassol, 2013, p. 143).

[Eu compro na Feira] porque geralmente no caso a salada deles, tu sempre consegue uma salada boa... no mercado geralmente é uma salada murcha... outras feiras que não sejam a dos colonos, fruteiras né, tu chega e a salada já tá 166 murcha. Então a qualidade pra mim é poder comprar esse produto fresco, que até o sabor é diferente [...] então o pessoal se identifica e compra porque sabe que o produto é caseiro, é feito em casa... por exemplo, eu sei que a massa deles é caseira, então sempre compro [...]. (Entrevista 10. Consumidora, 42 anos, professora) (Cassol, 2013, p. 144).

Portanto, a valorização dos alimentos da Feira e as justificativas de consumo se dão sobre aspectos imateriais, que estão relacionados à possibilidade de adquirir alimentos "frescos", "da própria terra", mais "saudáveis", que são produzidos na própria região e de uma maneira cultural específica.

Nesse sentido, a busca pelos produtos (alternativos) da Feira do Pequeno Produtor em Passo Fundo parece ser orientada por questões diferentes das dos consumidores do GAS. Enquanto os primeiros orientam suas práticas (alternativas) de consumo a partir da mobilização de valores 
sociais e culturais relacionados ao modo de fazer específico dos produtos, o qual está ligado a uma lembrança de um passado rural recente, os segundos parecem orientar suas práticas (alternativas) de consumo a estilos de vida sustentáveis e a preocupações políticas relacionadas ao meio ambiente e à produção de alimentos.

Os motivos dessas diferenças em buscar alimentos e acessar mercados alternativos, aparentemente semelhantes, decorre dos contextos sociais e culturais distintos, nos quais essas redes emergem. As características relacionadas à criação, estruturação, manutenção e funcionamento dessas redes - e os atores, instituições e as relações envolvidas diferem entre si pelo fato de que as características sociais e culturais (e históricas) são diferentes de acordo com cada contexto analisado.

No caso de Passo Fundo, a recente urbanização não foi capaz de romper os laços sociais e culturais de seus habitantes com o rural, os quais mantêm uma visão positiva dos modos de fazer e dos produtos "coloniais" comercializados na Feira. Já no caso italiano, a estruturação da rede do GAS e o consumo de seus produtos realizam-se sobre um compartilhamento de estilos de vida e de preocupações políticas relacionadas à preservação ambiental e às formas tradicionais de agricultura daquele país. Portanto, podemos dizer que, enquanto a Feira de Passo Fundo estrutura-se sobre um vínculo (cultural) rural comum entre as pessoas, a rede do GAS assenta-se sobre uma preocupação política tanto em relação ao meio ambiente como na manutenção dos pequenos agricultores no meio rural.

Conclui-se que as práticas sociais atreladas ao consumo de produtos alternativos relacionam-se com o contexto geral mais amplo e com os valores sociais e culturais ligados aos alimentos no interior desses contextos, assumindo assim características, formas de organização e significados diferentes. 


\section{0 papel do consumo e dos consumidores nas redes agroalimentares alternativas: Iocalidade, consumo reflexivo e valores sociais}

Conforme exposto, a consolidação das análises em torno da alimentação contemporânea - através das redes agroalimentares alternativas - faz emergir um novo ator ainda pouco estudado no Brasil: o consumidor de alimentos.

A compreensão da questão do consumo de alimentos é essencial para analisar como formas de produção e consumo diferenciadas vêm sendo construídas e se mantendo ao longo do tempo. Se as redes agroalimentares alternativas são capazes de ressocializar e relocalizar atores sociais e alimentos através do enraizamento social (embeddedness), também parece importante compreender os fatores pelos quais os consumidores estão buscando esse tipo de produto (alternativo).

Analistas envolvidos no entendimento dessas questões vêm chamando a atenção de que esse consumidor "alternati168 vo" não seria um ator marginal ao sistema convencional e que sua opção de comprar esses produtos não é necessariamente uma contraposição ao modelo. Antes disso, este consumidor estaria buscando satisfação pessoal, que pode estar ligada a preocupações com a saúde e o bem-estar, por exemplo.

No caso brasileiro, Guivant (2003), ao analisar o perfil e as motivações dos consumidores de produtos orgânicos em redes de supermercados, já havia distinguido dois tipos de consumidores: um deles - denominado ego-trip - caracterizado por indivíduos que consomem produtos orgânicos ocasionalmente, mas que seguem um estilo de vida saudável; o outro grupo - denominado ecológico-trip - caracterizado por indivíduos preocupados não apenas com a satisfação pessoal (estilo de vida saudável), mas também por questões políticas ligadas ao meio ambiente e à sociedade.

Barbosa (2009), também analisou as motivações da busca de produtos alternativos por parte dos consumidores e destacou que as questões de saudabilidade e a preocupação 
com a origem dos alimentos são importantes nas motivações desse tipo de consumo. Enquanto a primeira estaria ligada a preocupações em torno do valor nutricional dos alimentos e a prevenção de doenças, a segunda refere-se a questões de estilização do consumo, preocupação em consumir produtos produzidos através de relações justas e igualitárias (fair trade), além da busca por produtos típicos/artesanais, valorizando atributos de autenticidade, originalidade e naturalidade.

Radomsky (2010) também analisou o consumo de produtos ecológicos certificados e verificou que a busca por este tipo de alimento está vinculado a formas e estilos de vida adotados - tanto pelos consumidores, como pelos produtores agroecológicos. Assim, a legitimidade conferida ao selo (o atestado ecológico dos produtos) insere-se em um modo de viver e produzir do agricultor ecologista, muito mais do que pela formalização da certificação. São as relações sociais subjacentes a um modo específico de relacionar-se com a natureza e o ambiente, assentado em valores e identidades específicas, que também conferem distinção aos produtos. E este estilo de vida é compartilhado tanto por produtores/fornecedores como pelos consumidores.

Para D. Goodman, Dupuis e M. Goodman (2012), a questão da reflexividade em redes alimentares alternativas está ligada à capacidade de os consumidores articularem valores éticos e morais nas suas rotinas diárias de abastecimento alimentar e na sua reprodução social. Nessa perspectiva, as redes agroalimentares alternativas podem ser conceitualizadas como "comunidades de práticas reflexivas", nas quais consumidores e produtores criam novos espaços simbólicos e materiais em relação aos alimentos e à construção de mercados ${ }^{8}$.

\footnotetext{
8 Essas noções podem ser estendidas aos movimentos sociais de contestação do sistema agroalimentar convencional, tais como os movimentos de comércio justo, os movimentos de produtores orgânicos, as associações locais de consumidores e os conselhos municipais de alimentação, principalmente no caso europeu. No Brasil, o desenvolvimento dos "mercados institucionais" (PAA e PNAE) também ilustra esses processos.
} 
Especificamente em relação aos "consumidores verdes”, a prática consciente de buscar alimentos diferenciados (alternativos) pode ser vista como parte de um contexto relacional, no qual os consumidores estão inseridos. Neste caso, a reflexividade não deve ser vista como algo dado e isolado das práticas de consumo que ocorrem no interior das redes agroalimentares alternativas. Ao contrário, a reflexividade também implica um processo de expansão e construção de novas redes, significados e relações que permitem que as rotinas diárias de alimentação convencionais sejam substituídas por novas rotinas e padrões mais sustentáveis.

Segundo D. Goodman, Dupuis e M. Goodman (2012), os mercados alimentares alternativos devem ser submetidos a uma análise crítica para desconstruir o que denominam de "localismo reflexivo". Esse localismo é cotidianamente construído entre os diferentes atores sociais e instituições que fazem parte e atuam na manutenção desses mercados, 170 permitindo que valores sociais e culturais presentes nos territórios sejam valorizados e utilizados nesse processo.

Comparando os dois casos apresentados, percebe-se que, apesar de os consumidores integrantes do GAS italiano estarem mais vinculados a questões de saúde e sustentabilidade, o foco desse mercado se dá pelo atendimento de demandas alimentares diárias, sem intenção de ofertar produtos de alta qualidade, com apelo à tipicidade e a localidade. Ao contrário, essa rede se preocupa mais em desenvolver e ampliar relações que transformem o modelo alimentar dominante. Através da criação de uma esfera pública onde questões alimentares sejam pensadas, conhecidas e através das quais consumidores e produtores possam acordar sobre normas e regras alternativas.

Dessa forma, o caso italiano demonstra que muito mais do que a preocupação em consumir produtos saudáveis e produzidos localmente, há uma questão política (e reflexiva) mais geral em torno da produção de alimentos, que é com- 
partilhada pelos atores que fazem parte da rede e que contribuem para a mudança de práticas e rotinas de consumo.

No caso da Feira de Passo Fundo, o motivo principal da busca pelos produtos está relacionado à sua origem rural, muitas vezes um rural idealizado, romântico, que remete a formas sociais e alimentares diferenciadas (tradicionais) da contemporaneidade (Cassol, 2013). Não há aí - apenas indiretamente - uma preocupação política/ambiental em torno da busca de produtos locais mais saudáveis, mas uma representação associada aos alimentos que os distingue pela qualidade, que é atribuída ao interconhecimento e às relações sociais e pessoais estabelecidas com quem os produz.

Essas diferenças entre os dois casos examinados deixam claro que a busca por produtos "alternativos" - assim como a construção de redes agroalimentares alternativas - varia significativamente de acordo com os contextos sociais, culturais e históricos aos quais estão vinculados. Definir questões de consumo consciente, reflexivo, verde, sustentável, passa pelas características específicas de cada território no qual formas alternativas de produção e consumo se estruturam. A prática cotidiana de consumo desses produtos está vinculada aos valores culturais e sociais que as pessoas que vivem nestes espaços compartilham.

***

A contribuição deste artigo às reflexões sobre alimentação e consumo buscaram suscitar o debate em torno do papel desempenhado pelos consumidores na busca por alimentos produzidos e comercializados através de redes alternativas, assim como introduzir um conjunto de referências sobre o emergente campo de estudo da sociologia da alimentação.

A análise empreendida teve como propósito demonstrar a diversidade de formas de organização e as distintas dimensões pelas quais a alimentação pode ser interpretada 
contemporaneamente. Os casos estudados mostraram que essa diversidade se expressa na necessidade de incorporação de novos atores sociais à sua compreensão, assim como sugere uma boa reflexão sobre a ideia de que os mercados locais são formas de inclusão social dos pequenos agricultores. Neste sentido, é importante que as análises sociológicas do rural contemporâneo incorporem os mercados alimentares locais enquanto formas de inclusão social que vêm sendo construídas por diversos atores e que têm permitido a manutenção das famílias e dos conhecimentos e práticas de produção e alimentação locais.

Especificamente em relação ao consumo, a análise das redes alimentares sugere a necessidade de se examinar com acuidade as práticas cotidianas de consumo adotadas pelos indivíduos de tal forma a problematizar os motivos que levam os atores a adotar ou não práticas mais ou menos sustentáveis. O que nos leva a sugerir que o avanço dos estu172 dos sobre as formas alternativas de produzir e consumir alimentos deverá incorporar a análise das rotinas de consumo dos indivíduos (para além da análise de preços, tecnologias ou produtos "alternativos"), permitindo que se amplie o conhecimento sobre as causas e os condicionantes da busca por alimentos não convencionais.

Os dois casos empíricos analisados no artigo permitem concluir que há diferenças significativas nas rotinas de consumo por parte dos consumidores, sendo que, em cada um deles, as motivações, valores e atribuições relacionadas aos alimentos e ao seu consumo assumem características distintas. São essas comparações que julgamos necessárias ao entendimento do papel do consumo numa sociedade mais reflexiva. Mas a análise também demonstrou a importância que os valores sociais assumem na orientação dessas práticas de consumo e na estruturação de formas diferenciadas de produção e distribuição, permitindo a (re)valorização e o resgate de formas tradicionais e naturais associadas aos alimentos. 
Uma última conclusão que extraímos a partir da elaboração deste artigo nos leva a questionar o próprio foco dos estudos da sociologia rural no Brasil. Apesar de ser indiscutível que as questões ligadas aos temas agrários ainda são muito importantes nos estudos sociológicos, acreditamos que análises em torno de questões alimentares podem contribuir para ampliar e renovar esse campo de estudos, problematizando questões ainda pouco analisadas como a demanda crescente dos consumidores por alimentos diferenciados, a preocupação com a saudabilidade dos alimentos, a procedência, a forma de produzir e os potenciais efeitos ambientais gerados pelo processo produtivo.

Esse avanço analítico traria consigo novas questões e abriria uma senda de estudos sobre o rural, que poderia incorporar diversas dimensões e como a produção, o consumo e as práticas de alimentação vêm sendo estruturadas hodiernamente.

\section{Abel Cassol}

é doutorando em Sociologia pela Universidade Federal do Rio Grande do Sul (UFRGS) e pesquisador do Grupo de Estudos e Pesquisas em Agricultura Familiar e Desenvolvimento Rural (Gepad/CNPq).

\section{Sergio Schneider}

é professor de Sociologia do Desenvolvimento Rural e Estudos Alimentares na Universidade Federal do Rio Grande do Sul (UFRGS) e bolsista PQ/CNPq.

\section{BIBLIOGRAFIA}

BARBOSA, L. 2009. "Tendências da alimentação contemporânea". In: PINTO, M. de L.; PACHECO, J. K. (orgs.). Juventude, consumo e educação. Porto Alegre: ESPM.

BARBOSA, L.; CAMPBELL, C. 2006. "O estudo do consumo nas ciências sociais contemporâneas”. In: BARBOSA, L.; CAMPBELL, C. (orgs.). Cultura, consumo e identidade. Rio de Janeiro: FGV. 
BAUDRILLARD, J. 1995. Sociedade de consumo. São Paulo: Elfos.

BAUMANN, Z. 2007. Vida de consumo: a transformação das pessoas em mercadoria. Rio de Janeiro: Zahar.

BECK, U.; GUIDDENS, A.; LASH, S. 1995. Modernização reflexiva. São Paulo: Ed. Unesp.

BORN, B.; PURCELL, M. 2006. "Avoiding the local trap: scale and food systems in planning research". Journal of Planning Education and Research, n. 26, pp. 195-207.

BOURDIEU, P. 2007. A distinção: crítica social do julgamento. Porto Alegre: Zouk.

BRUNORI, G. 2007. "Local food and alternative food networks: a communication perspective". Anthropology of Food, S2, March. Disponível em: <http://aof.revues.org/430>. Acesso em: 11 fev. 2009. BRUNORI, G. et al. 2010a. Construire relazioni con I Grupi di Acquisto Solidale al di là della compra-vendita. Manuale di ARSIA: Agenzia Regionale per lo Sviluppo e L'Innovazione nel Settore Agricolo-Forestale. Toscana, Italia.

2010b. "Co-producing transition: innovation process in farms adhering to solidarity-based Purchase Groups (GAS) in Tuscany, Italy".

BUTTEL, F. H. 2001. "Some reflections on late twentieth century agrarian political economy”. Sociologia Ruralis, v. 41, n. 2, pp. 165-81.

CAROLAN, M. 2012. The sociology of food and agriculture. London/New York: Routledge.

CASSOL, A. 2013. Redes agroalimentares alternativas: mercados, interação social e a construção da confiança. Dissertação de mestrado em Sociologia. Porto Alegre: UFRGS.

DÍAZ MÉNDEZ, C.; GÓMEZ BENITO, C. 2004. "Sociología y alimentación”. Revista Internacional de Sociología, n. 40, pp. 21-46.

DÍAZ MÉNDEZ, C.; GÓMEZ BENITO, C. (coord.) 2008. Alimentación, consumo y salud. Barcelona: Obra Social, Fundación La Caixa.

DURKHEIM, E. 1996. As formas elementares da vida religiosa: o sistema totêmico na Austrália. São Paulo: Martins Fontes.

FERRARI, D. 2011. Cadeias agroalimentares curtas: a construção social de mercados de qualidade pelos agricultores familiares em Santa Catarina. Tese de doutorado em Desenvolvimento Rural. Porto Alegre: UFRGS.

FONTE, M. 2008. "Knowledge, food and place. A way of producing, a way of knowing”. Sociologia Ruralis, v. 48, n. 3, pp. 200-22. 
2010. "Food relocalisation and knowledge: dynamics for sustainability in rural areas". In: FONTE, M.; PAPADOPOULOS, A. G. (eds.). Naming food after places: food relocalization and knowledge dynamics in rural development. Farnham: Ashgate.

FRIEDMANN, H. 1993. "The political economy of food: a global crisis". New Left Review, London, n. 197, pp. 27-59.

FRIEDMANN, H.; McMICHAEL, P. 1989. "Agriculture and the State system: the rise and fall of national agricultures: 1870 to the present". Sociologia Ruralis, v. XXIX, n. 2, pp. 93-117.

GARCIA, M. F. 1992. "O segundo sexo do comércio: camponesas e negócio no Nordeste do Brasil”. RBCS - Revista Brasileira de Ciências Sociais, n. 19, pp. 84-102.

2008. "Mercado e modos de dominação: a Feira e as vinculações de trabalhadores na plantation açucareira nordestina”. In: NEVES, D.; SILVA, M. (orgs.). Processos de constituição e reprodução do campesinato no Brasil. v. 1: Formas tuteladas de condição camponesa. São Paulo: Ed. Unesp; DF: Núcleo de Estudos Agrários e Desenvolvimento Rural. GOODMAN, D. 2002. "Rethinking food production-consumption: integrative perspectives”. Sociologia Ruralis, v. 40, n. 4, pp. 271-77. GOODMAN, D.; DUPUIS, E.; GOODMAN, M. 2012. Alternative food networks. London/New York: Routlege.

GUIVANT, J. 2003. "Os supermercados na oferta de alimentos orgânicos: apelando ao estilo de vida ego-trip”. Ambiente $\mathcal{E}^{2}$ Sociedade, v. VI, n. 2, pp. 63-81.

GUIVANT, J. S.; SPAARGAREN, G.; RIAL, C. 2010. Novas práticas alimentares no mercado global. Florianópolis: Ed. UFSC.

HARVEY, M.; McMEEKIN, A.; WARDE, A. 2004. Qualities of food: alternative empirical and theoretical approaches. Manchester: Manchester University Press.

ILBERY, B.; BOWLER, I. 1998. "From agricultural productivism to postproductivism”. In: ILBERY, B. (ed.). The geography of rural change. London: Longman.

JACOBSEN, E.; DULSRUD, A. 2007. "Will consumers save the world? The framing of political consumerism". Journal of Agricultural and Environmental Ethics, v. 20, n. 5, pp. 469-82.

LANG, T. 2005. "What is food and farming for - the (re)emergence of health as a key policy driver". In: BUTTEL, F. H.; McMICHALE, P. New directions in the sociology of global development. S.1.: Cardiff University (Elsevier Research in Rural Sociology and Development, v. 11, pp. 123-44). 
LANG, T.; BARLING, D.; CARAHER, M. 2009. "The supply chain”. In: Food policy: integrating health, environment and society. Oxford: Oxford University Press.

LONG, N.; VAN DER PLOEG, J. D. 2011. "Heterogeneidade, ator e estrutura: para a reconstituição do conceito de estrutura”. In: SCHNEIDER, S.; GAZOLLA, M. (orgs.). Os atores do desenvolvimento rural: perspectivas teóricas e práticas sociais. Porto Alegre: Ed. UFRGS.

MARSDEN, T. K.; BANKS, J.; BRISTOW, G. 2000. "Food supply chain approaches: exploring their role in rural development". Sociologia Ruralis, n. 40, pp. 424-38.

MARSDEN, T. K.; BANKS, J.; RENTING, H. 2003. "Understanding alternative food networks: exploring the role of short food supply chains in rural development”. Environment and Planning A, n. 35, pp. 393-411.

MENNELL, S.; MURCOTT, A.; OTTERLOO, A. H. V. 1992. The sociology of food: eating, diet and culture. London: Sage.

MORGAN, K.; SONNINO, R. 2010. "The urban foodscape: world cities and the new food equation". Cambridge Journal of Regions, Economy and Society, n. 3, pp. 209-24.

176 POPKIN, B. M. 2011. "Agricultural policies, food and public health". EMBO Review, n. 12, pp. 11-18.

PORTILHO, F.; CASTANEDA, M.; CASTRO, I. R. R. 2011. “A alimentação no contexto contemporâneo: consumo, ação política e sustentabilidade”. Ciência Ẽ Saúde Coletiva, v. 16, n. 1, pp. 99-106.

RADOMSKY, G. F.W. 2010. Certificação participativa e regimes de propriedade intelectual. Tese de doutorado em Antropologia Social. Porto Alegre: UFRGS.

RITZER, G. F. 2007. La Mcdonaldización de la sociedad. Nueva edición revisada. Madrid: Editorial Popular.

SCARBELOT, M. 2012. A construção de cadeias agroalimentares curtas em Nova Veneza, SC. Dissertação de mestrado em Desenvolvimento Rural. Porto Alegre: UFRGS.

SEYFANG, G. 2009. The new economics of sustainable consumption. London: Palgrave McMillan.

SIMMEL, G. 1986. Sociología: estudios sobre las formas de socialización. v. 2. Madrid: Alianza Editorial.

SONNINO, R.; MARSDEN, T. 2006. "Beyond the divide: rethinking relations between alternative and conventional food networks in Europe”. Journal of Economic Geography, n. 6, pp. 181-89. 
THOMÉ DA CRUZ, F. 2012. Produtores, consumidores e a valorização de produtos tradicionais: um estudo sobre qualidade de alimentos a partir do caso do queijo serrano dos campos de cima da Serra/RS. Tese de doutorado em Desenvolvimento Rural. Porto Alegre: UFRGS.

VAN DER PLOEG, J. D. 1992. "El proceso de trabajo agrícola y la mercantilización”. In: GUZMAN, E. S. (ed.). Ecología, campesinato y historia. Madrid: Las Ediciones de la Piqueta.

VAN DER PLOEG, J. D. et al. 2000. "Rural development: from practices and policies towards theory". Sociologia Ruralis, v. 40, n. 4, pp. 391-407.

VEBLEN, T. 1988. A teoria da classe ociosa (um estudo econômico das instituições). 3. ed. São Paulo: Nova Cultural.

WARDE, A. 1997. Consumption, food and taste. London: Sage.

WARD, P.; COVENEY, J.; HENDERSON, J. 2010. Editorial "A sociology of food and eating: Why now?”. Journal of Sociology, v. 46, n. 4, pp. 347-51.

WEBER, M. 1991. Economia e sociedade: fundamentos da sociologia compreensiva. Brasília: EdUnb. 


\section{PRODUÇÃO E CONSUMO DE ALIMENTOS: NOVAS REDES E ATORES}

ABEL CASSOL

SERGIO SCHNEIDER

Resumo: Este artigo analisa o processo de constituição das novas formas de produção e consumo de alimentos e suas relações. Seu objetivo central consiste em verificar qual é o papel desempenhado pelos consumidores nesse processo. O campo de observação empírica para realização do estudo foram grupos coletivos de aquisição de alimentos da Itália e as feiras de venda direta no Rio Grande do Sul, Brasil, constituindo-se em dois casos específicos. Foram verificadas entre eles diferenças significativas nas rotinas de consumo por parte dos consumidores, cujas motivações, valores e atribuições relacionadas aos alimentos e ao seu consumo mostram características particularizadas. A contribuição deste artigo às reflexões sociológicas sobre alimentação e consumo consiste em suscitar o debate em torno do papel dos consumidores na produção e comercialização de alimentos através de redes alternativas.

Palavras-chave: Alimentação; Produção; Consumo; Redes Alimentares; Sociologia da Alimentação.

\section{PRODUCTION AND CONSUMPTION OF FOOD: NEW NETWORKS AND ACTORS}

Abstract: This article analyzes the process of constitution of new forms of production and consumption and their relationships. One of the it's main objective is to analyse the role of consumers in the process. The empirical observation of the study was to conduct by analysing two groups of food purchase, one in Italy and the other in the fairs of direct selling in Rio Grande do Sul, Brazil. We observe the existence of significant differences between these two 
groups related to the consumption routines by consumers, whose motivations, values and duties related to food and its consumption indicate specific features. One of the contributions of this paper to sociological reflections about food and consumption might be to foster and enlarge the debate about the role of consumers in the production and marketing of food through alternative networks.

Keywords: Food; Production; Consumption; Food Networks; Sociology of Food.

Recebido: 28/04/2015 Aprovado: 08/05/2015 